\title{
AN EXPLORATORY STUDY OF TRIAL AND ERROR IN THE DESIGN AND PRACTICE OF UNDERGRADUATE SEMINARS IN JAPAN
}

\author{
Wakako Fushikida \\ University Education Center, Tokyo Metropolitan University, Japan
}

\begin{abstract}
The purpose of this study is to investigate the solutions that faculty members resort to by trial and error in certain challenges presented to them in undergraduate seminars for second, third, and fourth year students. The research questions used were as follows: (1) What kind of problems do faculty members face, and (2) How faculty members try to improve their undergraduate seminars in order to provide an effective learning environment for students. Using a questionnaire, we conducted a survey on 157 faculty members and constructed the variables by factor analysis. The results indicated that faculty members usually try to set goals and activities with respect to the students' current situation or interests because they believe that the students do not have the basic knowledge and skills needed in specialized fields.
\end{abstract}

\section{KEYWORDS}

Higher Learning, Learning Community, Educational Psychology

\section{INTRODUCTION}

As we transition to a knowledge-based society, there is a great demand for individuals to have the abilities to survive in an unexpected future (Barnett 2012). For instance, much attention has been drawn to generic skills as the key to face and solve uncertainty problems. Though the name and usage of the skills is not uniform across countries and time periods, there is a common view that the concept of "generic skills" shows a potential for generalizability and possibility of diversion to other contexts (Australian National Training Authority 2003). Specifically, generic skills include not only basic skills such as reading, writing, thinking critically, information literacy, problem-solving skills, and human relation skills, represented by communication or teamwork, but also a sense of responsibility or flexibility. Those abilities and attitudes areexpected to be developed through interactive learning that promotes discussion and sharing of ideas among students (Ogata 2008).

In Japan, many faculty members and researchers consider an undergraduate seminar affectionately called "Zemi" as effective learning environment. It was in the nineteenth century when undergraduate seminars were born in Germany under the idea of "education through research" (Ushiogi 1986). A popular format of which is one where a faculty member and about 5 to 20 students participate in a regular meeting intended to help the students to gain a further understanding of their respective disciplines (e.g. Figure 1).

There are various activities in undergraduate seminars such as reading books and articles, conducting fieldwork, planning events or workshops, making presentations, asking questions, and writing graduation theses. Students are urged to collaboratively engage in solving practical problems and demonstrate knowledge and skills for two or three years in the same seminar (Yoshihara 2010). In other words, because of its importance as a teaching method, along with a lecture in university education, an undergraduate seminar also represents a research-oriented and a dialogue-based community of the faculty member and students, and offers students the opportunity for close interaction with faculty members. Therefore, through the seminars, the students may absorb ideas and tacit knowledge related to specialized fields through the use of daily communication. 


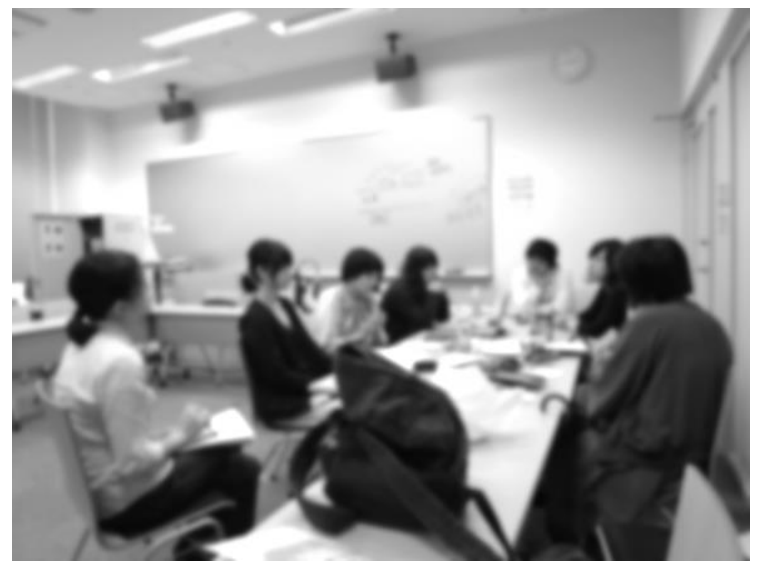

Figure 1. Example of learning activities in a seminar

(The woman leftmost in the photo is a faculty member watching her students discuss each other.)

Recently, some researchers have reported that undergraduate seminars are also effective for students in generating motivation and satisfaction, and in fostering generic skills. However, there are only a few empirical studies on undergraduate seminars from faculty members on perspectives about design, management, and assessment. Additionally, most faculty members do not have the chance to participate in and observe other seminar classes, so they need to explore other appropriate ways for establishing their original seminar styles.

This study investigate the solutions that faculty members resort to by trial and error in certain challenges presented to them in undergraduate seminars for second, third, and fourth year students. There two research questions used were as follows: (1) What kind of problems do faculty members face while designing and managing their original seminars, and (2) How faculty members try to solve the problems and improve their seminars' styles in order to provide an effective learning environment for students.

\section{METHODS}

A questionnaire survey using postal mail was conducted for various faculty membersto explore their perceptions about undergraduate seminars at the end of the 2015 . The seminars targeted by this study had to meet the following three prerequisites: (a) a formal name of the course is documented in the syllabus, (b) students can acquire units, (c) they are held periodically. The subjects of the study were full-time faculty members who belonged to humanities, social sciences, and integrated sciences, from universities with their headquarters located in Tokyo. The survey population had representation from 81 universities, where 525 of 14,355 faculty members were selected through a systematic random sampling.

The questionnaire items included age, gender, specialized field, age at which first seminar was started, the formal name of the seminar, scales of course design such as those of setting goals, activities, and instructions, and lastly, faculty members' practical experiences. The scales used in the questionnaires were created based on the results of previous studies and our preliminary surveys.

The purpose of this study was to clarify the common problems that faculty members encounter in undergraduate seminars, and find approaches that may be used for their improvement. First, after confirming the status of related items with extreme bias from the frequency distribution table, a correlation analysis was conducted. Second, the variables were constructed by factor analysis using the principal factor method with a promax-rotation. If an item with a communality $\leq 0.1$ was seen, that item was eliminated from the list and the factor analysis was re-performed. The number of factors was decided based on the criterion of eigenvalue $\geq 1$.

\section{RESULTS AND DISCUSSION}

Responses were received from 157 faculty members. However, cases with defects such as duplicate responses or no response to some questionnaire items were excluded. Eventually, data from the 130 viable 
responses were the subject of the analysis. Of the 130 faculty members, 92 were male $(70.8 \%)$ and 37 were female $(28.5 \%)$, with a mean age of 51.1 years $(S . D .=10.4)$. It was found that there were $30(23.1 \%)$ faculty members from humanities, $73(56.2 \%)$ from social sciences, and $22(16.9 \%)$ from integrated sciences.

To the question "what kind of difficulties did you have in practicing your undergraduate seminar?", the faculty members were required to answer 10 items on a 5-point scale. Table 1 showed that most faculty members answered that the following questionnaire items were particularly difficult problems: "There is variation in students' ability and motivation (average $=3.77$, S.D. $=1.00$ )", "Students do not read enough books" (average $=3.65$, S.D. =1.09), "Students' basic academic ability and knowledge are short" (average $=3.62$, S.D. $=1.02$ ), "Activating discussion among members" (average $=3.54$, S.D. $=1.19$ ), and "Providing instruction according to the students' current situation" (average=3.44, S.D. $=1.06$ ).

After conducting a factor analysis, as shown in Table 1, the first factor (Factor 1: F1) was named "Placing emphasis on learner centered activities and instructions" because a factor loads for items such as "provide instruction according to the students' current situation" and "Retaining balance between faculty members' expertise and students' interests." The second factor (Factor 2: F2) was named "shortage of basic academic literacy and motivation differences between individuals" because a factor loads for items such as "Students' are short of basic academic ability and knowledge" and "There is variation in students' ability and motivation". There is a middle level of correlation between F1 and F2 $(r=.47)$.

Finally, F1 and F2 scores were calculated by adding together each factor questionnaire items and analyzed using a one-way inter-subject analysis of variance to reveal the effects of years of experiences on difficult problems in faculty members' practical experiences. The average F1 score (average $=19.86$, S.E. $=.53$ ) was significantly higher than $\mathrm{F} 2$ score (average $=17.77$, S.E. $=.40$ ) based on the result of a Student $t$-test $(\mathrm{t}(113)=4.02, p=.00, d=.410,95 \% C I=.15-.67)$. The results in Figure 1 show that there were significant differences between $\mathrm{F} 2$ scores $\left(F(3,118)=3.072, p=.03, \eta^{2}=.072,95 \% C I=00-.16\right)$.

According to the Holm's sequentially rejective Bonferroni test, in the F2 scores, the score of less than a decade was significantly higher than the score of more than a decade, but less than 20 years $(d=.53,95 \% C I$ $=.11-.96)$ and the score of more than 30 years was significantly higher than the score of more than a decade, but less than 20 years $(d=.72,95 \% C I=.29-1.15)$. These findings indicate that the less than a decade and more than 30 years faculty members tended to recognize the difficulty in the design and practice of their undergraduate seminars.

Table 1. Results of factor analysis about difficult problems through faculty members' practical experience

\begin{tabular}{llrrrrr}
\hline \multicolumn{1}{c}{ Questionnaire items } & Average & S.D. & F1 & F2 & Communality \\
\hline (k) & $\begin{array}{l}\text { Providing instruction according to the students' } \\
\text { current situation. }\end{array}$ & $\underline{\mathbf{3 . 4 4}}$ & 1.06 & $\mathbf{. 8 5}$ & -.07 & .67 \\
\hline (i) & Allocating time required for activities properly. & 3.34 & 1.03 & $\mathbf{. 8 0}$ & -.16 & .54 \\
\hline (l) & $\begin{array}{l}\text { Establishing the design and management of the } \\
\text { seminar. }\end{array}$ & 3.01 & 1.04 & $\mathbf{. 7 0}$ & .03 & .50 \\
\hline (h) & $\begin{array}{l}\text { Retaining balance between faculty members' } \\
\text { expertise and students' interests. }\end{array}$ & 3.17 & 1.15 & $\mathbf{. 6 7}$ & .11 & .53 \\
\hline (j) & Activating discussion among members. & $\underline{\mathbf{3 . 5 4}}$ & 1.19 & $\mathbf{. 6 6}$ & .07 & .49 \\
\hline (g) & $\begin{array}{l}\text { Reflecting students' various interests in learning } \\
\text { topics and activities. }\end{array}$ & 3.15 & 1.14 & $\mathbf{. 6 5}$ & .08 & .48 \\
\hline (a) & $\begin{array}{l}\text { Students' are short of basic academic ability and } \\
\text { knowledge. }\end{array}$ & $\underline{\mathbf{3 . 6 2}}$ & 1.02 & .01 & $\mathbf{. 7 7}$ & .60 \\
\hline (d) Students do not read enough books. & $\underline{\mathbf{3 . 6 5}}$ & 1.09 & -.03 & $\mathbf{. 7 4}$ & .53 \\
\hline (c) $\begin{array}{l}\text { There is variation in students' ability and } \\
\text { motivation. }\end{array}$ & $\underline{\mathbf{3 . 7 7}}$ & 1.00 & -.06 & $\mathbf{. 7 5}$ & .53 \\
\hline (b) Students' overall motivation for learning is low. & 2.84 & 1.10 & .13 & $\mathbf{. 6 9}$ & .58 \\
\hline (f) Job-hunting causes negative participation and & 3.39 & 1.22 & -.07 & $\mathbf{. 4 0}$ & .14 \\
\hline & delays in the seminar activities. & Factor contribution & 3.75 & 3.18 & \\
& & Factor correlation & & .47 & \\
\hline
\end{tabular}




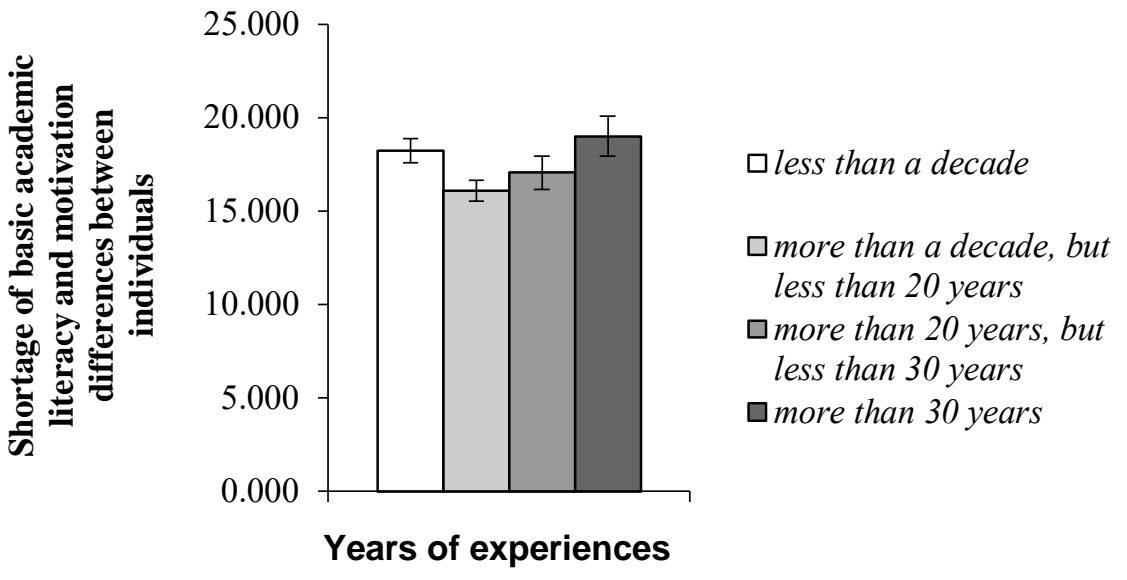

Figure 2. Results of the one-way analysis of variance (Error bars indicate the standard error)

\section{CONCLUSION}

These results indicated that faculty members try exceptionally hard to set goals and activities that cater to the students' current situations or interests, because they believe that students do not have the basic knowledge and skills needed in specialized fields. Furthermore, many faculty members seem to consider students' independent-minded stance for learning to be the most important thing, even if seminars have been thought to be professional education, based on faculty members' academic specialties in their previous studies. These findings are applicable in other educational methods, including the following elements: discussion among a faculty member and students, exploration of an academic discipline, and the sense of community.

Furthermore, beginning and expert faculty members find it extremely difficult to design and practice seminars such that students who lack some of the basic academic literacy skills and to students whose motivation levels are different between individuals. However, this research has not been able to explain the reason for the problem, so I would like to conduct additional analyses with free descriptions about faculty members' educational ideals for their seminars. It is also important to investigate the concrete process related to the above findings through periodic observation surveys of specific seminars and to offer supportive feedback to faculty members who are experiencing problems and difficulties.

\section{ACKNOWLEDGEMENT}

This work was supported by JSPS KAKENHI Grant Numbers 26885022 and 17 K1799000.

\section{REFERENCES}

Australian national training authority (2003) Defining generic skills: At a glance, 1-12. http://www.ncver.edu.au/publications/136.html (accessed 2013.07.07)

Barnett, R. (2012) Learning for an unknown future. Higher Education Research \& Development, 31(1):65-77.

Ogata, N. (2008) Student engagement and university education outcome. Japanese Association of Higher Education Research 11:45-64.

Ushiogi, M. (1997) Kyoto teikoku daigaku no chousen. Tokyo: Kodanshya.

Yoshihara, M. (2010) Evaluation and outcome of growth in generic skills. 2007 Basic Research (B) Evaluation of the outcome of Bachelor's Education and report of an international comparative study on fostering generic skills, 53-59. 